\title{
PERIODIZAÇÃO DO DESENVOLVIMENTO INFANTIL E A PRÁTICA DOCENTE NA PRÉ-ESCOLA: REFLEXÕES A PARTIR DA TEORIA HISTÓRICO-CULTURAL
}

\section{Janaína Pereira Duarte Bezerra}

Irineu Aliprando Tuim Viotto Filho

Rosiane de Fátima Ponce

Camila Cordeiro Becegato

Camila Rocha e Silva

Caroline Galan de Souza Pereira

Universidade Estadual Paulista

\section{Resumo}

O presente artigo tem origem nos trabalhos de intervenção com atividades ludopedagógica que realizamos com os membros do GEIPEEthc (Grupo de Estudos, Intervenção e Pesquisa em Educação Escolar e Teoria históricocultural), junto às crianças de uma escola municipal de educação infantil da cidade de Presidente Prudente/SP. O objetivo é tecer algumas reflexões acerca da prática docente na educação infantil, considerando a periodização do desenvolvimento das crianças a partir dos pressupostos teóricometodológicos da Teoria Histórico Cultural e, além disso, evidenciar que os professores atuantes na Educação Infantil, devem considerar a periodização do desenvolvimento das crianças na definição dos objetivos, planejamento e execução do trabalho pedagógico na escola. Enfatizamos a periodização do desenvolvimento na infância e suas principais características e peculiaridades, pois defendemos que ações de desenvolvimento histórico-culturais, engendradas pelos professores, possibilitarão as condições adequadas para a aprendizagem e o desenvolvimento qualitativo das crianças na educação infantil.

Palavras chaves: Teoria históricocultural, Periodização do desenvolvimento, Prática docente.

Olh@res, Guarulhos, v. 3, n. 1, p. 237-257. Maio, 2015. 


\title{
PERIODIZATION OF CHILDHOOD DEVELOPMENT AND TEACHING PRACTICE AT PRE-SCHOOL: REFLECTIONS FROM THE HISTORICAL AND CULTURAL THEORY
}

\begin{abstract}
This article originates from the intervention work with ludo-pedagogical activities which we've been doing at a public preschool located in Presidente Prudente/SP within members of the studies group called GEIPEEthc. Our objective is to make some reflections on teaching practice in early childhood education, considering the periodization of child development from the theoretical and methodological assumptions of Historical cultural theory. In this way, we showed that by acting in educational institutions, teachers should consider the periodization of child development, to get their educational objectives, as well as to plan their pedagogical proposals. For these reasons, this study aimed to discuss the timeline of development during childhood and emphasize the teaching practice contributions to children qualitatively development inside the childhood school.
\end{abstract}

Keywords: Historical cultural theory, periodization of development, Teaching practice. 
Janaína Pereira Duarte Bezerra; Irineu Aliprando Tuim Viotto Filho; Rosiane de Fátima Ponce; Camila Cordeiro Becegato \& Camila Rocha e Silva e Caroline Galan de Souza Pereira

\section{Introdução}

Este artigo tem como objetivo tecer algumas reflexões acerca da prática docente na educação infantil considerando a periodização do desenvolvimento das crianças a partir dos pressupostos teóricometodológicos da Teoria Histórico-Cultural (THC). Nesse sentido, cabe esclarecer que o motivo para delinearmos esta discussão originou-se nos trabalhos que desenvolvemos através de um projeto de extensão universitária, realizado com os membros do Grupo de Estudos Intervenção e Pesquisa em Educação Escolar e Teoria Histórico Cultural (GEIPEE-thc) e que considera a periodização do desenvolvimento das crianças, para estruturar as intervenções realizadas junto à uma escola pública de Educação Infantil da cidade de Presidente Prudente/SP.

O referido projeto de extensão originou-se de demanda da universidade para a realização de estágios em escolas públicas e, diante dessa condição, os membros do GEIPEE-thc, alunos de graduação, desenvolveram diferentes atividades no contato com a escola, desde observações sistemáticas e participantes no interior da escola e da sala de aula, até entrevistas com os professores e gestores, com a finalidade de estruturar intervenções de natureza ludo-pedagógicas com as crianças, valorizando a atividade do brincar, reconhecida como atividade principal de desenvolvimento de sujeitos em idade pré-escolar, em concordância com a periodização do desenvolvimento humano apregoada pela teoria histórico-cultural.

Dessa forma, nossa intenção foi possibilitar reflexões para a melhoria do trabalho pedagógico na escola de educação infantil, de modo a enfatizar a atividade do professor na superação de ações assistencialistas e na construção de um trabalho educativo que de fato proporcione desenvolvimento multilateral para as crianças na escola. 
Periodização do Desenvolvimento Infantil e a Prática Docente na Pré-Escola: Reflexões a Partir da Teoria HistóricoCultural

Vale destacar que a superação de ações assistencialistas corroboram com a superação de visões naturalizantes de desenvolvimento presentes na escola de educação infantil e que como afirma Haddad (2012), limitam-se a cuidados básicos e em deixar a criança aprender por si mesma na relação com os objetos do meio ambiente sem, no entanto, considerarem o processo de periodização vivido pelas crianças em idade pré-escolar como nos orienta a teoria histórico-cultural de desenvolvimento humano.

Nossas reflexões sobre o trabalho educativo do professor na escola de educação infantil enfatizam que atividades ludo-pedagógicas, quando realizadas a partir de ações intencionais e que consideram a atividade principal e orientadora do processo de desenvolvimento da criança, criam as máximas possibilidades para os sujeitos, pela via da apropriação dos conhecimentos científicos, artísticos e culturais, valorizando a aprendizagem escolar e o trabalho do professor nesse processo.

Para a realização do projeto de extensão/intervenção em questão utilizamos principalmente jogos e brincadeiras, dentre outras atividades lúdicas, com a finalidade de proporcionar situações diferenciadas de aprendizagem e desenvolvimento às crianças, e para isso nos amparamos principalmente, entre outros elementos teóricos, na periodização do desenvolvimento infantil, fato essencial para colocar a ciência à serviços da construção de metodologias de ensino e intervenção na escola.

É importante evidenciar que, ao propormos nossa intervenção junto às crianças, enfatizando a periodização do desenvolvimento infantil, buscamos contribuir para a orientação de uma prática pedagógica diferenciada na escola de educação infantil, além de possibilitarmos a reflexão acerca do papel do professor na construção de condições objetivas de aprendizagem das crianças, respeitando-as na sua condição, com vistas ao seu desenvolvimento multilateral e plena humanização.

Olh@res, Guarulhos, v. 3, n. 1, p. 237-257. Maio, 2015. 
Janaína Pereira Duarte Bezerra; Irineu Aliprando Tuim Viotto Filho; Rosiane de Fátima Ponce; Camila Cordeiro Becegato \& Camila Rocha e Silva e Caroline Galan de Souza Pereira

No sentido de defendermos um ensino de caráter desenvolvimentista, abordaremos alguns pontos importantes acerca da teoria histórico-cultural e, dentre eles, destacaremos a periodização do processo de desenvolvimento da criança, sobretudo e principalmente a partir de teóricos como Lev Semonovitch Vigotski (1896-1934), Alexander Romanovich Luria (1902-1977) e Alexei Nikolaievich Leontiev (19021979), que respaldados nos pressupostos do materialismo histórico dialético, tiveram como objetivo avançar concepções que naturalizam o desenvolvimento humano, rumo a construção de uma perspectiva voltada à compreensão do desenvolvimento social, histórico e cultural dos indivíduos.

Deste modo, podemos compreender que para a THC o processo de desenvolvimento humano "[...] é efetuado sob a influência determinante das condições de vida e de educação, tendo correspondência tanto com o meio ambiente quanto sob a influência diretriz do homem mais desenvolvido", como afirma Elkonin (2009, p. 193), fato que implica afirmar a importância do outro no desenvolvimento humano em geral e da criança em específico e, no interior da escola, vale salientar o papel crucial do professor, reconhecido como sujeito mais desenvolvido no processo de desenvolvimento da criança.

Nessa direção, portanto, enfatizamos que o processo de desenvolvimento humano-genérico deve ser objeto de preocupação da escola e dos professores, desde a mais tenra idade da criança, sobretudo porque essa possibilidade de desenvolvimento implica a apropriação de objetos culturais materiais e simbólicos disponíveis na sociedade e que possibilitarão a humanização dos seres humanos em direção à sua genericidade, ou seja, a sua constituição como um representante do gênero humano.

Olh@res, Guarulhos, v. 3, n. 1, p. 237-257. Maio, 2015. 
Periodização do Desenvolvimento Infantil e a Prática Docente na Pré-Escola: Reflexões a Partir da Teoria HistóricoCultural

Bezerra e Viotto Filho (2013, p.5), baseados em Heller (1977) e Duarte (1983), salientam que somente no processo de apropriação das objetivações genéricas como a filosofia, a arte, a ciência, a literatura, entre outras, é que será possível aos seres humanos superarem sua condição elementar (de um psiquismo elementar), para conquistarem e avançarem em direção da construção e desenvolvimento de um psiquismo de característica superior que oriente os seres humanos na efetivação de sua humanização a ser conquistada no bojo da cultura humana.

Sabemos que é pela via da apropriação de objetos culturais (materiais e simbólicos) que cada sujeito humano encontra condições de desenvolvimento e construção suas funções psicológicas superiores. No entanto, para efetivação dessas condições, principalmente no interior da sociedade capitalista alienada, a escola torna-se espaço essencial e local de construção de práticas pedagógicas que, respeitando o estágio de desenvolvimento do sujeito, faça-o avançar de uma condição em-si e cotidiana, para uma condição para-si, genérica, científica, humanizadora, como temos defendido nos nossos trabalhos e reflexões.

Referente à qualidade do ensino Vygotsky (2001) destaca que o bom ensino é aquele que se adianta ao desenvolvimento da criança, engendrando condições para o desenvolvimento de potencialidades significativas de cada sujeito e de acordo com o seu período de desenvolvimento.

Considerando essa condição de desenvolvimento potencial dos sujeitos a partir de situações histórico-culturais de aprendizagem, destacamos que essa situação deve ser engendrada por um sujeito mais desenvolvido culturalmente, que organize de forma intencional e sistematizada os conteúdos que as crianças vão se apropriar.

Olh@res, Guarulhos, v. 3, n. 1, p. 237-257. Maio, 2015. 
Janaína Pereira Duarte Bezerra; Irineu Aliprando Tuim Viotto Filho; Rosiane de Fátima Ponce; Camila Cordeiro Becegato \& Camila Rocha e Silva e Caroline Galan de Souza Pereira

No interior da escola este sujeito é o professor, ou seja, quem têm plenas condições de fazer a mediação de objetos advindos de uma cultura elaborada, sistematizada e pedagogicamente organizada, capaz de considerar a periodização do desenvolvimento infantil, tornando - a essencial para orientar a prática pedagógica e garantir que o processo de ensino - aprendizagem seja realmente qualitativo, desenvolvimentista e humanizador.

\section{Compreendendo a periodização do desenvolvimento e sua relação com a prática docente}

Antes de adentrarmos especificamente à compreensão da periodização do desenvolvimento infantil, vale destacar que esta não está alheia às condições concretas de vida do indivíduo, encontra-se, portanto, permeada por influências históricas e sociais do meio em que se vive, sendo que os professores devem reconhecer os estágios de desenvolvimento nos quais as crianças se encontram, para que possam intervir em seu desenvolvimento de forma adequada e visando contribuir com sua humanização (FACCI, 2004).

Cada período do desenvolvimento humano é caracterizado por Leontiev por um tipo de Atividade principal. Compete, portanto esclarecer que a atividade principal não é aquela que a criança realiza com maior frequência, mas sim a atividade "[...] cujo desenvolvimento governa as mudanças mais importantes nos processos psíquicos e nos traços psicológicos da personalidade da criança naquele determinado estágio de seu desenvolvimento" (LEONTIEV, 2006, p. 65).

Olh@res, Guarulhos, v. 3, n. 1, p. 237-257. Maio, 2015. 
Ainda de acordo com Leontiev (1978), o conceito de atividade principal refere-se às atividades nas quais os processos psíquicos se organizam ou tomam forma. Assim, a atividade principal não se configura como a única que a criança realiza ou aquela que ela mais tem interesse em realizar, mas sim, como a atividade que mais contribui para o desenvolvimento da criança de acordo com as suas condições psicológicas.

Assim, Vale evidenciar que embora em certo período de desenvolvimento determinada atividade é a que mais contribui para o desenvolvimento da criança, isto não significa que esta atividade desaparece quando a criança completa "a idade" da próxima atividade principal de desenvolvimento, como coloca LEONTIEV (2006, p. 65):

[...] embora, os estágios do desenvolvimento também se desdobrem ao longo do tempo de uma certa forma, seus limites de idade, todavia, dependem de seu conteúdo e este, por sua vez, é governado pelas condições históricas concretas nas quais está ocorrendo o desenvolvimento da criança. Assim, não é a idade da criança, enquanto tal, que determina o conteúdo de estágio do desenvolvimento; os próprios limites de idade de um estágio, pelo contrario, dependem de seu conteúdo e se alteram pari passu com a mudança das condições históricos - sociais.

Fica claro que, embora uma criança tenha determinada idade e nesta idade determinada atividade é a que mais vai proporcionar mudanças em seu desenvolvimento, isto não significa que ao avançar cronologicamente uma idade também avança-se a atividade principal, ela ainda pode permanecer em outra condição, como uma atividade secundária.

Referente a isso, Pasqualini (2009, p. 35) salienta que "[...] os processos constitutivos das linhas principais de desenvolvimento em uma idade

Olh@res, Guarulhos, v. 3, n. 1, p. 237-257. Maio, 2015. 
Janaína Pereira Duarte Bezerra; Irineu Aliprando Tuim Viotto Filho; Rosiane de Fátima Ponce; Camila Cordeiro Becegato \& Camila Rocha e Silva e Caroline Galan de Souza Pereira

convertem-se em linhas acessórias na fase seguinte, e o oposto também é verdadeiro". Diante dessa afirmação, podemos perceber então, a possibilidade de em determinados momentos da vida da criança sua aprendizagem ser orientada/dirigida a partir de sua atividade principal a qual deve ser conhecida pelo professor para ser objeto de desenvolvimento da criança na escola.

Salientamos que a compreensão acerca da periodização do desenvolvimento na infância a partir da THC evidencia a superação da compreensão mecânica e positivista que apregoa um desenvolvimento natural do sujeito; na perspectiva histórico-cultural esse processo é mediado nas relações sociais e por objetos culturais essenciais, como demonstraremos na discussão.

A comunicação emocional com os adultos é a primeira atividade principal da criança que vai do nascimento ao primeiro ano de vida. Ao nascerem, as crianças necessitam das mediações de um adulto para imprimir, ao longo de seu desenvolvimento, uma consciência humana permeada por impressões auditivas, táteis, que favorecerão o surgimento da linguagem/comunicação para a incorporação ao mundo social.

A criança se comunica emocionalmente com o adulto antes mesmo de ser capaz das mais simples ações com objetos. A criança ainda não conhece as palavras, não entende a conduta do adulto, mas se alegra com sua presença, observa o adulto por períodos longos, capta as palavras e os sorrisos que lhes dirige. (MUKHINA, 1996, p. 47).

Vale destacar que, neste período do desenvolvimento, os interesses e necessidades das crianças estão, a todo o momento, ligados aos adultos Olh@res, Guarulhos, v. 3, n. 1, p. 237-257. Maio, 2015. 
Periodização do Desenvolvimento Infantil e a Prática Docente na Pré-Escola: Reflexões a Partir da Teoria HistóricoCultural

que as cercam, nada mais tem condições de suprir as necessidades. Assim, neste momento, é de suma importância que o professor entenda como deve ser sua relação com o bebê a fim de que esta relação tenha qualidade humanizadora, e que possa avançar em direção a formação de ações sensório-motoras de manipulação, que serão terminantemente importantes para a atividade principal do próximo período de desenvolvimento da criança.

É importante colocar que no primeiro ano de vida da criança, esta já começa balbuciar, elemento que precede a linguagem, e sobre a linguagem FACCI (2004, p. 68), destaca que a primeira função da linguagem é a comunicação, um meio de expressão e compreensão entre os homens, que permite o intercâmbio social. A autora ainda salienta que até aproximadamente os dezoito meses de vida, a criança ainda não consegue descobrir as funções simbólicas da linguagem, que é uma operação intelectual consciente e altamente complexa a ser conquistada posteriormente.

Para Mello (2006), a origem da comunicação infantil está diretamente relacionada às ações dos adultos. Assim, no interior da escola, o professor deve ser um sujeito interlocutor, que viabilizará a necessidade da criança se comunicar. Trata-se de um momento irrevogavelmente importante para que a criança tenha uma nova necessidade.

Facci (2004, p. 68) destaca que por volta dos dois anos de idade, a criança apresenta grande evolução da linguagem, iniciando uma forma totalmente nova de comportamento, exclusivamente humana. Neste período, há inicio da formação da consciência e a diferenciação do "eu" infantil. O “(...) pensamento da criança evolui em função do domínio dos meios sociais do pensamento, quer dizer, em função da linguagem" (Vygotski, 1993, p. 116).

Olh@res, Guarulhos, v. 3, n. 1, p. 237-257. Maio, 2015. 
Janaína Pereira Duarte Bezerra; Irineu Aliprando Tuim Viotto Filho; Rosiane de Fátima Ponce; Camila Cordeiro Becegato \& Camila Rocha e Silva e Caroline Galan de Souza Pereira

O desenvolvimento da linguagem, portanto, assume a mediação entre o sujeito e o objeto do conhecimento, além de corroborar com o desenvolvimento sensório-motor da criança e, consequentemente, o interesse que ela, a criança, tem pelos adultos quando mais nova passa a ser direcionado à manipulação simples de objetos, o que caracteriza a próxima atividade principal, a ação com os objetos, característica da próxima fase de seu desenvolvimento (MUKHINA, 1996).

Julgamos importante destacar que estabelecer relações com os objetos ainda que de maneira simples, condição que possibilitará a mudança de uma atividade principal para outra, trata-se de um processo que demanda tempo, além de pressupor a necessidade da criança ter atingido determinada qualidade psíquica para alcançar tal mudança.

Atingida esta condição, há possibilidade para o desenvolvimento da atividade objetal manipulatória, atividade principal das crianças ainda na primeira infância, mais precisamente do primeiro aos três anos e seis meses. Essa atividade corresponde à necessidade de que haja objetos do cotidiano adulto, cujo domínio se coloca como desafiador para a criança.

Percebemos que neste período de desenvolvimento, a maioria das crianças, inicialmente, seguram o objeto, posteriormente o soltam, levam à boca, aproximam o objeto dos olhos, balançam, jogam ou simplesmente deixam o objeto para focarem sua atenção em outra situação. Nessa etapa, os objetos ainda não possuem funções sociais para as crianças, são apenas manipulados de forma aleatória, como determina esta fase (objetalmanipulatória) do processo de desenvolvimento infantil.

É, portanto, necessário que a criança se aproprie das reais funções e atributos sociais dos objetos, a partir de mediações intencionais e ações claras e, dessa forma, concordamos com Martins (2009), quando afirma que ao adulto, sujeito mais desenvolvido culturalmente, é conferida a Olh@res, Guarulhos, v. 3, n. 1, p. 237-257. Maio, 2015. 
Periodização do Desenvolvimento Infantil e a Prática Docente na Pré-Escola: Reflexões a Partir da Teoria HistóricoCultural

condição de comunicação verbal com a criança, pois somente assim é possível oferecer os objetos que a rodeiam, denominando-os, considerando os seus significados, usos sociais e suas características físicas.

Assim sendo, durante a realização do projeto de intervenção junto às crianças da escola, proporcionamos, dentre outras atividades, vivências de manipulação e experimentação de instrumentos musicais de brinquedo, onde as crianças puderam aprender a manipular diferentes instrumentos como pandeiros, tambores, violões, chocalhos e outros instrumentos e, simultaneamente, assumirem papeis sociais tais como cantores, sambistas e instrumentistas, dentre outras atividades de natureza lúdica, apropriando-se, paulatinamente, da função social de tais objetos culturais.

O contato que a criança estabelece com os adultos e o uso social dos objetos que a rodeiam, a colocam em condições de se apropriar deles conhecendo e reconhecendo suas funções sociais. A ação de manipular os objetos de várias formas, onde a criança atua para explorar as diferentes partes, sensações, gostos e outras sensações dos objetos torna-se essencial ao seu desenvolvimento posterior e voltado à compreensão dos significados sociais dos mesmos, fato possibilitado pela compreensão da linguagem e que será de crucial importância para a paulatina aprendizagem e desenvolvimento infantil.

Diante dessa compreensão, salientamos que o papel do professor, sobretudo ao proporcionar condições de aprendizagem e desenvolvimento, permeados pela sua orientação verbal e condizente com a realidade das crianças, torna-se crucial, como foi possível demonstrar na execução das atividades do projeto de extensão/intervenção que realizamos.

Olh@res, Guarulhos, v. 3, n. 1, p. 237-257. Maio, 2015. 
Janaína Pereira Duarte Bezerra; Irineu Aliprando Tuim Viotto Filho; Rosiane de Fátima Ponce; Camila Cordeiro Becegato \& Camila Rocha e Silva e Caroline Galan de Souza Pereira

No referido projeto, para atingir as crianças, o professor, utilizou-se de palavras, conjugando-as corretamente, assim como denominou os objetos pelos seus nomes e funções adequadamente. Isso aconteceu visando possibilitar situações de aprendizagem e desenvolvimento da criança pois, como salienta Saviani (2000) a escola não é lugar para o senso comum, e para a linguagem cotidiana, mas sim, para a socialização das formas mais desenvolvidas do saber historicamente acumulado pela humanidade.

A apropriação das funções sociais dos objetos remete a criança à uma utilização adequada e com maior precisão deles, além da fiel reprodução da forma de utilização que os adultos imprimem aos objetos. Defendemos que o avanço de uma condição elementar para uma condição superior de desenvolvimento não aconteceria sem a participação efetiva do adulto, sua linguagem e sua experiência social compartilhada com a criança, pois é ele quem tira ou concede o objeto, quem o nomeia e socializa seu significado. A relação entre a criança e o objeto só é possível mediante o surgimento e o desenvolvimento da linguagem.

É importante salientar que em nossas atividades de intervenção houve momentos específicos para as crianças cantarem e dançarem diferentes músicas, devidamente orientadas pelo professor, condição que possibilitou às mesmas assumirem papeis de dançarinos, cantores, sambistas, dentre outros papéis artísticos, fato que viabilizou condições para o desenvolvimento de importantes processos imaginativos mais elaborados e complexos acerca da realidade; foi interessante perceber que durante e após as vivências os relatos das crianças já se apresentavam mais elaborados e com muita riqueza de detalhes sobre as características dos objetos e os papeis sociais decorrentes da atividade artístico-musical com elas realizada.

Olh@res, Guarulhos, v. 3, n. 1, p. 237-257. Maio, 2015. 
Todo exposto até o presente momento nos remete refletir que durante o segundo ano de vida da criança, as propostas de atividades educativas acerca da atividade objetal manipulatória devem, entre outros objetivos, orientar ações facilitadoras da compreensão da linguagem direcionada às crianças pelos adultos.

\begin{abstract}
Ainda que a verbalização própria se restrinja a poucas palavras; que ocupam, inclusive, o lugar de orações inteiras; sob condições de estimulação, a compreensão pela criança pode ser bastante ampla. Neste sentido, é fundamental a associação entre palavras e objetos (ou imagens), a exposição da criança a um vocabulário rico e, acima de tudo, que o adulto dirija-se à criança sempre, com a máxima clareza, no que se inclui uma dicção correta. MARTINS (2009, p. 111112).
\end{abstract}

Toda estruturação ora apresentada possibilita à criança um vasto conhecimento sobre os objetos e a função social que desempenham, contribuindo para que, assim, haja o aumento acerca do interesse da criança em explorar e conhecer cada vez mais sobre o mundo em que vive.

Daqui, a conclusão pedagógica da necessidade de alargarmos a experiência da criança, se quisermos proporcionar à sua atividade criadora uma base suficientemente sólida. Quanto mais veja, escute e experimente, quanto mais aprenda e assimile, quanto mais abundantes forem os elementos reais de que disponha na sua experiência, tanto mais importante e produtiva será, mantendo-se idênticas as restantes circunstâncias, a atividade da sua imaginação. (VIGOTSKI, 2009, p. 18).

Ainda na idade pré-escolar (três anos e meio aos seis anos de idade), percebe-se que as crianças apresentam a necessidade de que seus desejos sejam realizados de forma rápida e praticamente imediata e os objetos sociais tem importante função na realização de tais desejos. Assim,

Olh@res, Guarulhos, v. 3, n. 1, p. 237-257. Maio, 2015. 
Janaína Pereira Duarte Bezerra; Irineu Aliprando Tuim Viotto Filho; Rosiane de Fátima Ponce; Camila Cordeiro Becegato \& Camila Rocha e Silva e Caroline Galan de Souza Pereira

Vigotski (apud PRESTES, 2010), afirma que, não é possível encontrar uma criança que queira fazer algo no futuro e para isso planeje sua ação a longo prazo.

Para Vigotski (2008) essa situação de necessidade de satisfação imediata dos desejos é a condição necessária para o surgimento da atividade do brincar, terceira atividade principal da criança na escala de seu desenvolvimento que vai dos três anos e meio aos seis anos de idade, a idade pré-escolar, como já evidenciamos anteriormente.

Nesse contexto, em concordância com a afirmação de Vigotski, nos preocupamos em criar situações desafiadoras, a fim de que, por meio da atividade do brincar, as crianças pudessem superá-las avançando, assim, no seu processo de desenvolvimento. Para tanto, solicitávamos que assumissem papéis sociais tais como, instrumentistas, sambistas e cantores, dentre outros, para comporem uma banda musical e, simultaneamente, solicitávamos que assumissem o papel de dançarinos, bailarinos e passistas de samba, realizando os passos de determinada coreografia que demonstrávamos, para que, de forma lúdica e numa direção pedagógica, os sujeitos pudessem aprender e se desenvolver.

Vigotski (2008) coloca que dependendo das motivações e tendências internas já elaboradas na criança, é no interior das brincadeiras que elas aprendem a agir com base em uma esfera cognitiva avançando, paulatinamente, a esfera externa. Isto quer dizer que, diferentemente do que acontece com as crianças um pouco maiores, para um bebê, os objetos possuem uma força determinadora, ou seja, os objetos ditam à criança o que ela deve fazer com eles.

A ação sobre o objeto favorece um estágio de transição de seu significado, por meio de, uma condição imaginária, na busca de satisfazer desejos não realizados da criança, sobre $\mathrm{o}$ mundo adulto. Olh@ res, Guarulhos, v. 3, n. 1, p. 237-257. Maio, 2015. 
Isto representa uma tamanha inversão da relação da criança com a situação concreta, real e imediata, que é difícil subestimar seu pleno significado. A criança não realiza toda essa transformação de uma só vez porque é extremamente difícil para ela separar o pensamento (o significado de uma palavra) dos objetos. (VIGOTSKI, 2008, p. 115).

Para Vigotski (apud PRESTES, 2010), a imaginação é o critério que deve ser adotado para distinguir a brincadeira de outras atividades da criança. É a imaginação que, de acordo com Arce e Simão (2006, p. 72), proporciona à criança a possibilidade de assumir, durante a brincadeira, diferentes papeis sociais como ser bombeiro, médico, cozinheira, ou seja, realizar ações do mundo adulto que lhe são inacessíveis no momento.

\begin{abstract}
O que é primordial na brincadeira é que ela reflete a vida; a criança brinca de situações reais que não podem ser vividas na vida real por ela naquele momento. Ela cria a situação imaginária a que Vigotski atribui um papel importante, pois é nesse momento, nessa idade, que surge a divergência entre o campo visual e o semântico. (VIGOTISK, 2010, p. 158, apud PRESTES).
\end{abstract}

O fato de assumir papéis coloca a criança na condição de vivenciar as ações praticadas por outrem, sobretudo quando utiliza objetos, funções, profissões, atos rotineiros e dá vida ao que pôde captar anteriormente em suas experiências. Quando passa a denominar-se nos objetos ou nas ações por meio das atividades que cria, a criança está exercendo o jogo protagonizado/brincadeira de papéis sociais (ARCE; SIMÃO, 2006).

A origem do jogo protagonizado possui uma relação genética com a formação, orientada pelos adultos, das ações com os objetos na primeira infância. Denominamos ações com os objetos os modos sociais de utilizá-los que se formaram ao longo da história e agregados a objetos determinados. Os autores dessas ações são os adultos. Nos objetos não se indicam diretamente os modos de

Olh@res, Guarulhos, v. 3, n. 1, p. 237-257. Maio, 2015. 
Janaína Pereira Duarte Bezerra; Irineu Aliprando Tuim Viotto Filho; Rosiane de Fátima Ponce; Camila Cordeiro Becegato \& Camila Rocha e Silva e Caroline Galan de Souza Pereira

\begin{abstract}
emprego, os quais não podem descobrir-se por si sós à criança durante a simples manipulação, sem a ajuda nem a direção dos adultos, sem um modelo de ação. O desenvolvimento das ações com os objetos é o processo de sua aprendizagem sob a direção imediata dos adultos. (ELKONIN, 2009, p. 216).
\end{abstract}

As atividades em que as crianças puderam assumir diferentes papeis foram condição para satisfazerem as necessidades que criamos, como dançar como bailarinos, tocar instrumentos como se estivessem em uma banda musical ou fossem sambistas, dentre outras formas lúdicas de assunção de papéis sociais.

Salientamos que a brincadeira nessas condições, proporciona superação de necessidades, seja de manipulação dos objetos e sua experimentação, seja a realização de desejos decorrentes de sua vivência no mundo adulto, considerando, sobretudo, os objetos que toma contato, assim como os papéis que assume na atividade do brincar.

Podemos afirmar que dessa forma, ou seja, por meio da atividade do brincar e considerando as suas possibilidades de aprendizagem e desenvolvimento, as crianças puderam vivenciar situações próprias do mundo adulto, isso na condição de protagonistas de tais atividades e, dessa forma, superar desafios e atender as suas necessidades em direção ao seu desenvolvimento e humanização.

Defendemos, portanto, que os professores devem desempenhar importante papel no desenvolvimento das crianças, principalmente ao terem clareza e conhecimento acerca da condição que tange a periodização do desenvolvimento infantil. Ao atuarem na educação infantil, podem utilizar esse aparato teórico para respaldar suas práticas pedagógicas, objetivando a aprendizagem e desenvolvimento complexo

Olh@res, Guarulhos, v. 3, n. 1, p. 237-257. Maio, 2015. 
Periodização do Desenvolvimento Infantil e a Prática Docente na Pré-Escola: Reflexões a Partir da Teoria HistóricoCultural

das crianças como uma etapa a ser atingida e diretamente ligada ao desenvolvimento das atividades principais anteriormente desenvolvidas.

Dessa maneira, a realização da prática docente terá condições de reconhecer as instituições de educação infantil como um rico espaço de apropriação e objetivação da cultura humana, um espaço onde as crianças tomarão contato com os objetos humanos, seus usos e suas funções sociais, e desenvolverão uma capacidade tipicamente humana - a abstração - utilizada por filósofos, cientistas, compositores, construtores, enfim, por todos os seres humanos que pensam, imaginam, memorizam, planejam discutem, criam, e organizam suas vidas a partir de realidades anteriormente vividas e em decorrência de terem vivido um processo de aprendizagem e desenvolvimento humanizador.

\section{Considerações finais}

As discussões sobre o desenvolvimento infantil, presentes na teoria histórico-cultural, nos indicam que a criança se apropria da cultura humana por meio de mediação estabelecida com um adulto ou com outras crianças mais desenvolvidas. Por isso, buscamos neste trabalho, enfatizar o papel do professor e sua prática docente no processo de humanização das crianças da escola de educação infantil e, para isso, a relevância de reconhecer as atividades principais que marcam a periodização do desenvolvimento humano.

Considerando esse pressuposto para o trabalho do professor, defendemos que às instituições educacionais cabem a sistematização dessa condição de ensino, sobretudo porque não é possível organizar uma situação de

Olh@res, Guarulhos, v. 3, n. 1, p. 237-257. Maio, 2015. 
Janaína Pereira Duarte Bezerra; Irineu Aliprando Tuim Viotto Filho; Rosiane de Fátima Ponce; Camila Cordeiro Becegato \& Camila Rocha e Silva e Caroline Galan de Souza Pereira

ensino sem objetivos e possibilidades reais de aprendizagem para as crianças, principalmente na educação infantil.

É necessário garantir uma condição de desenvolvimento para as crianças no interior da escola, de maneira a mediar o conhecimento a partir dos períodos de desenvolvimento em que a criança se encontra, oferecendolhe aquilo que realmente contribuirá para seu processo de humanização.

Defendemos, portanto, que o conhecimento acerca da periodização do desenvolvimento das crianças difundido por autores da teoria históricocultural, assim como uma mediação devidamente organizada, intencional e sistematizada, possibilitarão condições efetivas para que as crianças avancem em seu processo de aprendizagem e desenvolvimento, vivenciando experiências educativas enriquecedoras, pois somente através dessas possibilidades educativas histórico-cultural é que a prática docente será realmente significativa no que tange o desenvolvimento humano-genérico das crianças no interior da escola.

Finalizamos esse artigo, enfatizando a importância da escola e do professor no processo de desenvolvimento da criança na educação infantil, sobretudo porque as possibilidades de acesso e apropriação de objetos culturais qualitativamente diferenciados produzidos pela humanidade, dentre eles os objetos artístico-culturais e acadêmicocientíficos, encontram-se no interior das escolas e não nas características engendradas pela vida cotidiana.

Olh@res, Guarulhos, v. 3, n. 1, p. 237-257. Maio, 2015. 
Periodização do Desenvolvimento Infantil e a Prática Docente na Pré-Escola: Reflexões a Partir da Teoria HistóricoCultural

\section{Referências}

ARCE, A.; SIMÃO, R. A psicogênese da brincadeira de papéis sociais e/ou jogo protagonizado na psicologia do jogo de D. B. Elkonin. In: ARCE, A.; DUARTE, N. (Orgs.). Brincadeira de papéis sociais na educação infantil: as contribuições de Vigotski, Leontiev e Elkonin. São Paulo: Xamã, 2006. p. 65-88.

BEZERRA, J.P.D.; VIOTTO FILHO, I.A.T. A criança em idade pré-escolar e as funções psicológicas superiores: focando a atividade ludo-pedagógica para o processo de desenvolvimento da imaginação. Publicado em 17 de setembro de 2013. Disponível em: <http://www.histedbr.fe.unicamp.br/acer_histedbr/jornada/jornada11/artigos/5/artigo_simp osio_5_101_janaina_dsp@hotmail.com.pdf> Acesso em: 15 abr. 2015.

DUARTE, N. A individualidade para-si. Campinas:Autores Associados, 1983.

ELKONIN, B. B. Psicologia do jogo. São Paulo: Martins Fones, 2009.

FACCI, M G. D. A periodização do desenvolvimento psicológico individual na perspectiva de Leontiev, Elkonin e Vigostski. Cad. Cedes, Campinas, vol. 24, n. 62, p. 64-81, abril 2004.

HADDAD, 1. Políticas integradas de educação e cuidado infantil: desafios, armadilhas e possibilidades. Cadernos de Pesquisa, São Paulo, v. 36, n. 129, p. 519-546, set./dez. 2012.

HELLER, A. Sociologia de la vida cotidiana. Barcelona: Península, 1977.

LEONTIEV, A. O desenvolvimento do psiquismo. Lisboa: Livros Horizonte, 1978.

LEONTIEV, A. N. O desenvolvimento do psiquismo. Tradução de Manuel Dias Duarte. 3. ed. Lisboa: Horizonte Universitário, 2006.

MARTINS, L. M. O ensino e o desenvolvimento da criança de zero a três anos. In: ARCE, A.; MARTINS, L. M. Ensinando aos pequenos: de zero a três anos. Campinas: Alínea, 2009. p. 93-121.

MELLO, S. A. Contribuições de Vigotski para a Educação Infantil. Em Mendonça, S. G. L., \& Miller, S. (Orgs.), Vygotsky e a Escola Atual: fundamentos teóricos e implicações pedagógicas. Araraquara: Junqueira \& Marin, 2006.

MUKHINA, V. Psicologia da idade pré-escolar. São Paulo: Martins Fontes, 1996.

PASQUALINI, J. C. A perspectiva histórico-dialética da periodização do desenvolvimento infantil Psicologia em Estudo. Universidade Estadual de Maringá: 2009. Vol 14. Olh@res, Guarulhos, v. 3, n. 1, p. 237-257. Maio, 2015. 
Janaína Pereira Duarte Bezerra; Irineu Aliprando Tuim Viotto Filho; Rosiane de Fátima Ponce; Camila Cordeiro Becegato \& Camila Rocha e Silva e Caroline Galan de Souza Pereira

Disponível em: <http://www.redalyc.org/articulo.oa?id=287122120005 ...> Acesso em: 17 $\operatorname{dez} 2014$.

SAVIANI, D. Escola e Democracia: teorias da educação, curvatura da vara, onze teses sobre educação e política. 33. ${ }^{a}$ ed. revisada. Campinas: Autores Associados, 2000.

VIGOTSKI, L. S. A formação social da mente. 7. ed. Tradução de José Cipolla Neto, Luís Silveira Menna Barreto, Solange Castro Afeche. São Paulo: Martins Fontes, 2008.

. A Imaginação e a Arte na Infância. Lisboa: Relógio D’ Água, 2009.

A brincadeira e o seu papel no desenvolvimento psíquico da criança. Revista Virtual de Gestão de Iniciativas Sociais, Rio de Janeiro, p. 23-36 jun. 2008a. Disponívelem:http://xa.yimg.com/kq/groups/32960205/729519164/ame/artigo+ZOIA+PRE STES.cg-.pdf: Acesso em: 17 dez 2014.

VYGOTSKY, L. S. Aprendizagem e desenvolvimento intelectual na idade escolar. In: VYGOTSKY, L. S.; LURIA, A. R.; LEONTIEV, A. N. Linguagem, desenvolvimento e aprendizagem. 10. ed. São Paulo: Ícone, 2010.

. Pensamento e Linguagem. São Paulo: Martins Fontes, 1993.

. Psicologia pedagógica. São Paulo: Martins Fontes, 2001.

Recebido para publicação em 20 de dezembro de 2014

Aprovado em 01 de abril de 2015

Olh@res, Guarulhos, v. 3, n. 1, p. 237-257. Maio, 2015. 